\title{
Beburughen Becce' Dalam Saloka Madura Sebagai Nasehat Bagi Auditor
}

\author{
Moh. Baqir Ainun ${ }^{1}$, Tyasha Ayu Melynda Sari ${ }^{2}$ \\ , Universitas Wiraraja ${ }^{1}$, Universitas Muhammadiyah Surabaya ${ }^{2}$ \\ baqirainun@wiraraja.ac.id ${ }^{1}$, tyasha.ams28@gmail.com ${ }^{2}$
}

\begin{abstract}
Abstrak
Setiap etnis dan budaya memiliki keunikan dan mengandung etika baik bagi masyarakat. Berbagai nasehat dan petuah dari orang tua, guru, maupun pimpinan suku dapat disampaikan dengan cara-cara unik seperti melalui pribahasa khas budaya itu sendiri. Paper ini mengeksplorasi bagaimana beburughen becce' (nasehat bagus) yang terkandung pada saloka Madura dapat menjadi nasehat bagi auditor dalam melaksanakan proses audit, sehingga skandal-skandal akuntansi seperti Arthur Andersen dan Enrontidak terulang kembali. Metode penelitian yang digunakan adalah studi literatur yang diperoleh dari berbagai sumber. Paper ini menjelaskan bahwa beburughen becce' (nasehat bagus) yang terkadung dalam saloka Madura seperti pakoh ngenneng ka kaju (paku menancap pada kayu), lakona lakone kennengnganna kennengnge (pekerjakannya kerjakan tempatnya tempati), mon kerras paakerres (jika keras harus berkeris), oreng jhujhur mate ngonjhur (orang jujur mati berselonjor), dan manis jhe' dhuli kalodhu' pae' jhe, dhuli paloa (manis jangan langsung ditelan pahit jangan langsung diludahkan) dapat memberikan nasehat bagi auditor untuk melaksanakan audit dengan independen, bertanggung jawab, objektif, integritas, dan skeptis.
\end{abstract}

Kata kunci: saloka Madura, beburughen becce', nasehat, etika auditor

\begin{abstract}
Every ethnicity and culture is unique and contains good ethics for society. Various advice and advice from parents, teachers, and tribal leaders can be conveyed in unique ways such as through the typical proverb of the culture itself. This paper explores how beburghen becce' (good advice) contained in saloka Madura can be advice for auditors in carrying out the audit process so that accounting scandals such as Arthur Andersen and Enron do not recur. The research method used is the study of literature obtained from various sources. This paper explains that beburughen becce' (good advice) contained in saloka Madura such as pakoh ngenneng ka kaju (nails stuck to wood), lakona lakone kennengnganna kennengnge (employees work on the place they live in), mon kerras paakerres (if it is hard it must be crispy), oreng jhujhur mate ngonjhur (honest people die long), and sweet jhe' dhuli kalodhu' pae' jhe' dhuli paloa (sweet, don't swallow bitter, don't immediately spit it out) can provide advice for auditors to carry out audits with independence, responsibility, objectivity, integrity, and skeptical.
\end{abstract}

Keywords: saloka Madura, beburghen becce', advice, auditor ethics 


\section{Pendahuluan}

Auditor harus menunjukkan dedikasi tinggi dan berkesinambungan untuk mencapai kinerja terbaik. Kinerja auditor yang buruk akan menimbulkan konsekwensi negatif terhadap perusahaan (Afifah et al., 2015), seperti kasus Arthur Andersen yang telah menjadi sejarah buruk dalam dunia akuntan (Duska et al., 2011, p. 9).

Peran auditor sangat penting untuk membuktikan keakuratan gambaran keuangan perusahaan untuk digunakan pengguna dalam proses pengambilan keputusan (Duska et al., 2011, p. 114). Peran auditor dalam laporan keuangan telah dan terus menjadi masalah penting (Masoud, 2017) karena auditor merupakan penjaga integritas keuangan (Duska et al., 2011, p. 123).

Kualitas audit yang dihasilkan oleh auditor merupakan kunci ketepatan pengambilan keputusan investasi oleh investor, dimana kualitas audit yang dihasilkan bergantung pada kode etik yang telah ditetapkan (Pflugrath et al., 2007) dan etika yang dimiliki oleh auditor itu sendiri seperti independen, kompeten, bertanggung jawab, dan objektif (Zahmatkesh dan Rezazadeh, 2017).

Etika dan perilaku etis merupakan objek yang tetap menarik untuk selalu dibahas terkait dengan profesi akuntan terlebih setelah terjadinya kasus Enron dan KAP Arthur Andersen yang berdampak sangat luas terhadap perekonomian dunia. Kasus etika ini melahirkan aturan Sarbanas Oxley Act sebagai upaya untuk mencegah terjadinya kasus yang sama di kemudian hari.

Dalam perkembangannya, penelitian etika mulai dikaitkan dengan etnis dan budaya tertentu. Hal ini terjadi karena etnis dan budaya merupakan salah satu sumber dari etika dan perilaku etis. Setiap etnis memiliki dan menganut norma yang mengandung nilai kearifan dari suatu budaya lokal untuk dijadikan sebuah panutan hidup (Djasuli, 2017), maupun sebagai indikator dalam menilai perilaku individu atau kelompok dalam sebuah kelompok (Azis et al., 2015).

Terkait dengan penelitian akuntansi, Efferin (2015) mengungkapkan bahwa penelitian akuntansi sudah saatnya berkembang lebih jauh dari pada hanya sekedar membuktikan teori dan mendukung kemapanan. Penelitian yang dimaksud termasuk dalam penelitain terkait dengan etika para akuntan itu sendiri. Dengan demikian, diharapakan akuntansi sebagai disiplin ilmu sosial dapat memberikan kontribusi yang besar untuk merubah dunia menjadi lebih baik.

Selain itu, penelitian para akademisi yang menggali etika dalam akuntansi dari sudut pandang etnis dan kebudayaan secara tidak langsung dapat menunjukkan kekayaan etnis dan budaya di suatu Negara. Budisusetyo dan Subroto (2012) meneliti tentang dilema etika dengan menggunakan istilah jawa teposliro dan semuci untuk menyatakan bahwa seseorang yang memiliki sikap 
tenggang rasa dan sikap sok suci dikaitkan dengan perilaku auditor. Purnamawati (2018) meneliti tentang tradisi Nampah Batu di Bali Indonesia dan menemukan adanya etika integritas yang dimiliki oleh masyarakat sehingga meskipun pengelola memiliki akses yang luas, namun tidak pernah melakukan penyelewengan dana karena adanya nilai niskala yang dianut. Apriliani dan Abdullah (2018) menulis sebuah paper yang mengungkap etika perusahaan dalam melaksanakan Corporate Social Responsibilty (CSR) dengan menggunakan falsafah Tanjidor dan menemukan bahwa perusahaan seharusnya melaksanakan CSR bukan semata-mata hanya untuk memenuhi aturan, namun juga harus dengan niat tulus untuk menyenangkan hati masyarakat layaknya Tanjidor yang merupakan sarana mencari nafkah disertai tujuan untuk menghibur masyarakat.

Penelitian-penelitian serupa seperti Pertiwi dan Ludigdo (2013) yang meneliti tentang CSR dengan budaya Tri Hita Karana yang merupakan filosofi keseimbangan hidup masyarakat Hindu di Pulau Bali. Azis et al. (2015) yang memaknai independensi auditor dari sudut pandang siri' na pacce yang merupakan budaya Bugis-Makasar Indonesia. Lutfillah et al. (2016) yang mengamati dan menginterpretasikan tanggung jawab auditor berdasarkan nilai budaya Jawa Memayu Hayuning Bawana. Fitria dan Syakura (2017) yang meneliti tentang akuntabilitas akuntan dari sudut pandang budaya keroan suku Kutai Samarinda Kalimantan Timur Indonesia. Beberapa penelitian ini menunjukkan bahwa nilai-nilai budaya memiliki keberagaman dan terdapat unsur kebajikan yang patut untuk diikuti dan mendukung ditegakkannya etika profesi, sehingga dapat menjadi kontrol dan acuan hidup (Misnadin, 2012).

Madura merupakan salah satu suku yang ada di Jawa Timur Indonesia. Masyarakat Madura memiliki panutan norma agama Islam dan norma budaya yang digunakan sebagai landasan hidup (Djasuli, 2017). Semua tradisi kebudayaan Madura baik dalam bentuk kesenian seperti kerapan sapi, maupun dalam bentuk wajengan-wajengan khas Madura dalam kehidupan sehari-hari mengandung norma-norma kabajikan. Salah satu norma budaya Madura disampaikan melalui saloka yang merupakan sebuah istilah khas Madura untuk menyampaikan baburughen becce' (nasehat baik) dalam bentuk kata-kata bijak layaknya peribahasa (Misnadin, 2012). Saloka Madura yang sarat dengan baburughen becce' digunakan oleh masyarakat Madura sebagai landasan dalam menjalankan kehidupan sehari-hari mulai dari lingkungan keluarga sampai dengan lingkungan kerja.

\section{Metodologi Penelitian}

Penelitian ini merupakan penelitian kualitatif yang bersifat fleksibel dan tidak terikat dengan aturan-aturan tertentu (Moleong, 2005). Penelitian ini menyelidiki sebuah fenomena berupa kebudayaan Madura, yaitu saloka Madura 
yang mengandung beburughen becce' (nasehat bagus) terkait dengan etika-etika yang harus dimiliki oleh auditor.

Studi literatur dilakukan dalam penelitian dengan mengumpulkan sumbersumber terkait dengan saloka Madura, selanjutnya dilakukan pemilihan terkait dengan saloka Madura yang mengandung beburughen becce' yang sesuai dengan etika-etika yang harus dimiliki oleh auditor. Tahap selanjutnya adalah mengaitkan beburughen becce' yang terkandung dalam saloka Madura dengan etika auditor. Etika yang harus dimiliki oleh auditor seperti independensi, tanggung jawab, integritas, objektifitas, dan skeptisme akan dianalisis dan dibahas berdasarkan perspektif saloka Madura. Bagaimana saloka Madura telah memberikan beburughen becce' yang apabila dijadikan patokan dalam melaksanakan proses audit tidak akan terjadi kasus-kasus kecurangan auditor.

\section{Hasil Dan Pembahasan Independensi}

Independensi merupakan suatu hal yang instrumental untuk mendukung ketergantungan pengguna pada proses pelaporan keuangan dan meningkatkan efisiensi manajemen (Duska et al., 2011, p. 125).

Audit independen merupakan perkara penting terkait dengan penjaminan kinerja keuangan yang bebas dari salah saji material sehingga kepercayaan terhadap pasar modal dan nilai pasar sebuah perusahaan akan meningkat (Irmawan et al., 2013). Hadirnya independensi juga merupakan satu-satunya alasan kenapa profesi auditor masih dibutuhkan dalam dunia bisnis (Moore, Tetlock, Tanlu, dan Bazerman, 2006).

Bagi seorang auditor, independensi merupakan prinsip dasar yang benarbenar harus tertanam dalam diri auditor agar perannya sebagai auditor dapat bermanfaat (Azis et al., 2015). Independensi auditor merupakan sumber kehidupan dalam profesi audit sehingga hasil audit tanpa independensi tidak memiliki nilai yang berarti (Johnstone et al., 2001). Independensi auditor merupakan elemen kunci yang sangat penting terkait dengan kualitas audit yang akan dihasilkan (Irmawan et al., 2013), dan menjadi anteseden mendasar untuk skeptisisme profesional (Chiang, 2016).

Dalam praktiknya, auditor tidak pernah terlepas dari tekanan yang terjadi terkait dengan independensi yang dimilikinya. Hal yang paling umum adalah ketergantungan auditor terhadap klien terkait dengan fee audit dan keberlangsungan perikatan audit. Auditor dalam suatu kondisi tertentu akan mengalami dilema etis antara kepentingan publik untuk melaksanakan audit independen dan kepentingan pribadi terkait dengan keberlangsungan perikatan audit di masa yang akan datang. Azis et al. (2015) manyatakan bahwa hubungan 
antara auditor dan klien dapat menjadi rumit karena adanya ketergantungan ekonomi terkait dengan fee audit.

Dilema etis yang seperti demikian bukanlah sesuatu yang mengejutkan. Pasalnya Kantor Akuntan Publik (KAP) besarpun tidak akan lepas dari tekanan klien seperti skandal akuntansi legendaris Arthur Andersen dan Enron. Tidak dapat dipungkiri bahwa ketergantungan Arthur Andersen terhadap Enron terkait dengan pendapatan terbesar Arthur Andersen yang diperoleh dari jasa non audit yang diberikan pada akhirnya menciptakan bencana besar.

Independensi yang harus dimiliki oleh seorang auditor sebenarnya telah terkandung dalam saloka Madura sebagai beburughen becce' yang sering disampaikan oleh orang tua kepada anaknya, guru kepada muridnya, maupun tokoh masyarakat kepada masyarakat awam. Saloka Madura yang dimaksud adalah pakoh ngenneng ka kaju yang memiliki arti paku menancap pada kayu. Saloka ini memiliki pesan bahwa orang Madura harus memiliki pendirian yang teguh (Nugraha, 2017).

Saloka Madura pakoh ngenneng ka kaju biasa digunakan oleh masyarakat Madura untuk saling mengingatkan agar selalu teguh pendirian, berpegang teguh terhadap norma-norma agama dan budaya, dan tidak mengindahkan tekanan dari orang lain. Dalam istilah Madura, hal ini biasa disebut sebagai anggep angin lebat yang artinya anggap angin lewat. Selama orang Madura berada pada jalan yang benar maka tidak perlu ada hal yang perlu ditakutkan.

Dalam profesi auditor, maka penting kiranya auditor untuk tetap bersikukuh dan independen dalam melaksanakan tugas audit. Auditor tidak perlu mengindahkan tekanan dan ancaman yang dilakukan oleh klien. Auditor tidak perlu takut untuk mengungkapkan yang sebenarnya meski kemungkinan besar perikatan audit di tahun depan tidak akan dilakukan lagi oleh klien. Auditor harus yakin bahwa hilangnya pendapatan dengan tidak berlanjutnya perikatan audit di masa yang akan datang karena prinsip auditor untuk mempertahankan independensinya akan mendapat balasan yang sepadan. Terkait dengan hal ini, saloka Madura juga memberikan beburughen becce' atau nasehat baik maskea bada e lag-ellaghenna naghe mon pajhet rajhekkena paste kalowar yang mempuyai arti meskipun ada di kerongkongan naga jika memang rejekinya pasti akan keluar. Saloka ini mengajarkan untuk memasrahkan rejeki kita kepada kehendak Allah SWT, karena tugas manusia hanya berusaha sebaik mungkin sesuai dengan aturan-aturan yang ada seperti firman Allah dalam Al-Qur'an Surat Ath-Thalaq ayat 3 sebagai berikut:

وَمَنْ يَتَوَكَّنْ عَلَى اللَّهِ فَهُهُ حَنْبُه

"Dan barangsiapa yang bertawakal kepada Allah niscaya Allah akan mencukupkan (keperluan)nya". 
Dari saloka Madura dan Firman Allah diatas maka tidak perlu kiranya auditor merasa khawatir pendapatannya akan berkurang karena diancam untuk diganti dengan auditor yang lain apabila tidak menuruti kemauan klien. Auditor hanya perlu tetap bersikap independen dan melakukan tugasnya, sedangkan urusan rejeki (pendapatan dan fee audit) sudah menjadi takdir yang tidak akan tertukar dengan yang lainnya.

Dalam praktiknya, etika dari auditor memang tidak seidealis dengan apa yang dipaparkan diatas. Hal ini bisa dilihat dari banyaknya kasus pelanggaran etika termasuk di Indonesia. Berdasarkan data dari Pusat Pembinaan Profesi Keuangan (PPPK), Kementerian Keuangan, diketahui bahwa per 21 Januari 2019, jumlah akuntan publik yang aktif adalah 1.368 orang publik. Dari sumber yang sama juga diketahui terdapat beberapa akuntan yang mendapat sanksi terkait dengan ketidak patuhannya terhadap kode etik termasuk rusaknya independensi yang dimilikinya. Hal ini menunjukkan bahwa dari sekian banyak auditor di Indonesia tentu masih ada beberapa auditor yang memiliki etika buruk dan melakukan pelanggaran. Pada dasarnya peristiwa ini merupakan kejadian yang manusiawi. Saloka Madura menyebutnya dengan tellor sapatarangan ta' kera becce' kabbhi yang artinya telur satu sarang tidak akan bagus semua. Saloka ini mengandung pesan bahwa dari setiap wilayah (biasanya desa) dan kelompok pasti ada anggotanya yang menjadi perusak karena perilakunya yang kurang baik. Terkait dengan profesi auditor, maka sudah barang tentu bahwa tellor sapatarangan (sekelompok profesi auditor) ta' kera becce' kabbhi (ada anggota yang melakukan pelanggaran).

Jika auditor memegang prinsip sesuai dengan saloka Madura yang memberikan beburugan becce' setiap saat seperti yang telah dijabarakan diatas meliputi pakoh ngenneng ka kaju (paku menancap pada kayu), anggep angin lebat (anggap anngin lewat), maskea bada e lag-ellaghanna nagha mon pajhat rajhekkena paste kalowar (meskipun ada di kerongkongan naga jika memang rejekinya pasti akan keluar), dan bhengo' pote tolang tembeng pote mata (lebih baik putih tulang dari pada putih mata) maka independensi dari seorang auditor dalam melaksanakan audit tidak akan pernah diragukan, dan kasus-kasus pelanggaran tentang pelanggaran independensi tidak akan pernah menciderai reputasi profesi auditor di dunia.

\section{Tanggung Jawab}

Pada dasaranya tanggung jawab merupakan perkara penting yang harus dimiliki oleh setiap orang termasuk seorang auditor. Lutfillah et al. (2016) menyatakan bahwa auditor memiliki tanggung jawab kepada profesinya, kepada publik, dan kepada Allah. Hal ini menunjukkan bahwa auditor memiliki dua 
hubungan yaitu hubungan sesama manusia dan hubungan dengan Allah. Hubungan dengan manusia (hablum minannaas) terjalin antara auditor dengan profesinya serta auditor dengan publik, sedangkan hubungan dengan Allah (hablum minallah) terjalin antara auditor sebagai makhluq dengan Allah sebagai khaliq.

Auditor harus mempertanggung jawabkan hasil pekerjaannya kepada profesinya dalam wujud menjaga citra baik dari profesi auditor. Auditor tidak boleh menjadi penghianat terhadap profesinya dengan melakukan kecurangan yang pada akhirnya akan menciderai reputasi dan kredibilitas dari profesi akuntan publik atau auditor.

Auditor juga harus bertanggung jawab kepada publik dengan cara memberikan opini yang tepat terhadap suatu laporan keuangan (Lutfillah et al., 2016). Hal ini karena opini yang diberikan oleh aditor akan sangat menentukan keputusan investasi yang akan diberikan oleh investor. Auditor memiliki tanggung jawab untuk mendeteksi salah saji material pada laporan keuangan, sehingga diharapkan dapat melindungi kepentingan publik dari informasi keuangan yang menyesatkan dalam proses pengambilan keputusan (Dean et al., 2002), meski pihak yang membayar auditor bukan publik tapi klien (Duska et al., 2011, p. 118).

Selain itu, auditor sebagai seorang makhluq memiliki tanggung jawab kepada Allah sebagai sang khaliq. Hal ini telah tercantum dalam Al-Quran surat Al Mudtastsir ayat 38 sebagai berikut:

"Tiap-tiap diri bertanggung jawab atas apa yang telah diperbuatnya."

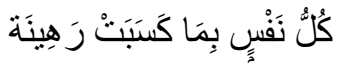

Apabila auditor menyadari dan sadar sepenuhnya bahwa tanggung jawab sebagai auditor memiliki tiga dimensi yang sangat penting dan pada akhirnya akan kembali kepada dirinya sendiri jika diabaikan, maka sudah tentu auditor tidak akan pernah mencoba untuk melakukan penyelewengan dan kecurungan dalam melaksanakan tugasnya. Hal ini karena mereka sadar bahwa Allah tidak menyukai hamba-hambanya yang berbuat kecurangan, bahkan Allah mengutuknya seperti yang telah tertulis dalam Al-Qur'an.

Saloka Madura memberikan bhebhurughen becce' pada para auditor untuk bertanggung jawab sebagai satu-satunya harapan investor untuk menjamin bahwa informasi dalam laporan keuangan perusahaan telah bebas dari salah saji material. Lakona lakone kennengnganna kennengnge yang memiliki arti pekerjakannya kerjakan tempatnya tempati, merupakan sebuah nasehat untuk selalu mengerjakan sesuatu sesuai dengan tugas dan tanggung jawabnya. Saloka ini juga memberikan nasehat bahwa setiap pekerjaan yang telah dilakukan sesuai dengan tugasnya harus dipertanggung jawabkan. 
Dalam kehidupan sehari-hari masyarakat Madura, saloka Madura lakona lakone kennengnganna kennengnge biasa disampaikan sebagai nasehat agar setiap orang melaksanakan tugas dan fungsinya masing-masing dengan penuh tanggung jawab. Seorang suami misalnya yang bertugas untuk melindungi dan menafkahi keluarga harus malaksakanakan tugasnya tersebut dengan penuh tanggung jawab. Jika orang Madura tidak melakasanakan tugas dan fungsinya sebagai wujud tanggung jawab maka masyarakat akan memberikan sanksi berupa pandanganpandangan negatif. Orang Madura yang seperti demikian biasanya disebut akanta pappa'an takae' (seperti tembakau yang dipapah orang tua yang tersangkut) sebagai perumpamaan yang disampaikan untuk seseorang yang tidak berguna sama sekali.

Auditor yang bertugas untuk memberikan jaminan kepada investor dari informasi yang menyesatkan karena salah saji laporan keuangan serta bertanggung jawab kepada publik, profesinya, dan Allah harus dilakukan dengan sebaikbaiknya. Auditor harus lakone lakona kennengnge kennenganna untuk mengabdikan diri kepada publik, profesinya, serta Allah SWT, sehingga auditor benar-benar menjadi pihak yang berguna, bermanfaat dan tidak menjadi pappa'an takae'.

\section{Objektifitas}

Objektfitas merupakan kondisi pikiran yang memberikan nilai kepada seorang auditor untuk tidak memihak, jujur, intelektual, dan bebas dari konflik kepentingan (Duska et al., 2011, p. 87). Objektivitas dari seorang auditor harus selalu dijaga dan menghindari hal-hal yang dapat merusak kejujuran dan okjektivitasnya (Zahmatkesh dan Rezazadeh, 2017).

Rusaknya objektifitas yang dimiliki oleh auditor akan berdampak pada kualitas audit yang akan dihasilkan. Hal ini terjadi karena bercampurnya sifat subjektif dari auditor yang biasanya diawali dengan rusaknya independensi. Independensi dan objektifitas memiliki hubungan yang erat. Apabila independensi dari auditor telah cidera maka sudah dapat dipastikan bahwa auditor tidak akan mampu melakukan pekerjaannya dengan tingkat objektivitas yang maksimal. Kasus Arthur Andersen misalnya, ketergantungan ekonomi dari Arthur Andersen terhadap Enron berupa \$27 juta yang diperoleh dari jasa non audit (lebih besar dari pendapatan audit sebesar \$25 juta) menyebabkan cideranya independensi Arthur Andersen dan pada akhirnya sulit untuk bersikap objektif dalam melakukan audit terhadap Enron.

Dalam hal ini, saloka Madura pakoh ngenneng ka kajuh seperti yang telah dijelaskan diatas tepat disampaikan kepada auditor sebagai beburughen becce, agar auditor tidak goyah dan mampu mempertahankan independensinya sehingga 
setiap keputusan yang akan diambil dapat dilakukan dengan objektif dan tidak memihak kepada salah satu pihak.

Auditor sebagai pihak yang berkuasa dalam memberikan opini terhadap laporan keuangan perusahaan hendaknya menggunakan kewenangannya dengan adil, bijak, dan tidak berat sebelah karena hal demikian akan membuat keresahan dan ketidak puasan masyarakat atau publik. Telah banyak skandal akuntansi yang timbul karena keberpihakan auditor terhadap klien seperti Arthur Andersen dan Enron. Keberpihakan ini pada akhirnya menyebabkan keresahan dan ketidak puasan investor, karyawan Enron, profesi Akuntan Publik, dan pelaku pasar Dunia.

Investor resah karena mereka adalah pihak yang benar-benar dirugikan terkait dengan informasi palsu yang mereka terima melalui laporan keuangan yang menyesatkan. Karyawan Enron resah karena dengan kasus ini mereka kehilangan pekerjaannya. Profesi Akuntan Publik resah karena citra mereka yang ikut tercoreng dimata publik. Pelaku pasar Dunia juga resah karena skandal Arthur Andersen dan Enron menyebabkan ketidak stabilan perekonomian di Dunia.

Kasus ini menunjukkan bahwa auditor merupakan profesi yang seharusnya membawa konsep rahmatan lil 'alamin karena begitu besarnya dampak kerusakan jika mereka melanggar aturan-aturan yang telah ditetapkan, dan berbuat sewenang-wenang demi memuaskan nafsu pribadi. Allah berfirman dalam AlQur'an surat Al-Hujurat ayat 9 sebagai berikut.

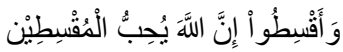

"Dan berlaku adillah. Sesungguhnya Allah menyukai orang-orang yang berlaku adil."
}

Penjelasan diatas baik berupa saloka Madura dan ayat Al-Qur'an menunjukkan bahwa objektifitas merupakan etika yang harus dimiliki dan diamalkan oleh seorang auditor dalam melaksanakan audit. Tanpa objektifitas, kewenangan auditor untuk memberikan opini terhadap laporan keuangan klien akan sulit untuk dilakukan dengan bijak dan adil, sehingga akan menciptakan keresahan-keresahan karena kecurangan-kecurangan yang dilakukan seperti kasus Arthur Andersen dan Enron.

\section{Integritas}

Untuk menjaga dan memperluas kepercayaan publik, seorang auditor harus melakukan semua tanggung jawab profesionalnya dengan integritas tertinggi (Duska et al., 2011, p. 84). AICPA Code of Ethics mendefinisikan integritas sebagai elemen karakter mendasar untuk memperolah pengakuan profesional. Integritas mengharuskan auditor untuk jujur dan terus terang dalam batasan kerahasiaan klien. Integritas diukur dalam sesuatu yang benar dan adil. Komitmen 
akuntan terhadap integritas adalah yang terpenting dan membuka jalan bagi independensi auditor sejati, yang berfungsi sebagai landasan profesi (Jelinek, 2018).

Terkait dengan hal ini maka auditor sudah seharusnya menyampaikan semua temuan yang diperoleh dalam masa pengauditan. Auditor tidak dibenarkan apabila menyembunyikan kecurangan yang terjadi di perusahaan. Meski demikian, auditor harus tetap membicarakan temuan ini dengan klien untuk dimusywarahkan dan menemukan keputusan yang terbaik dengan tetap berpegang teguh pada prinsip independensi.

Dalam saloka Madura, orang tua dan para sesepuh Madura telah memberikan nasehat kepada masyarakat Madura untuk selalu menjunjung tinggi sikap jujur dalam kehidupan sehari-hari. Kejujuran merupakan kunci untuk mencapai kesuksesan yang hakiki. Saloka Madura menyampaikan bahwa oreng jhujhur mate ngonjhur yang artinya adalah orang jujur mati berselonjor. Saloka ini dalam kehidupan sehari-hari dijadikan sebuah landasan untuk bersikap jujur jika ingin menjadi orang yang beruntung dalam hidup dan matinya.

Pentingnya sikap jujur bagi orang Madura sesuai dengan firman Allah dalam Al-Qur'an surat Al-Baqarah ayat 42 sebagai berikut.

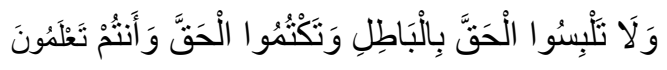

"Dan janganlah kamu campur adukkan kebenaran dengan kebatilan dan (janganlah) kamu sembunyikan kebenaran, sedangkan kamu mengetahuinya."

Melalui saloka dan firman Allah diatas, maka auditor hendaknya harus memiliki sikap jujur dalam wujud integritas yang tinggi dalam melaksanakan proses audit. Jika auditor dapat menjadikan saloka dan firman di atas sebagai pegangan dalam menjalankan tugasnya, maka skandal-skandal kecurangan auditor seperti Arthur Andersen dan Enron tidak perlu terjadi. Dalam kasus tersebut telah jelas bagaimana auditor tidak dapat menerapkan integritasnya, sehingga tidak menyampaikan apa yang sebenarnya terjadi. Auditor telah berani berbohong dan mengingkari kodratnya sebagai penjaga integritas keuangan demi kepentingan pribadi, dan pada akhirnya berujung pada hancurnya Arthur Andersen dan Enron.

Skandal ini menunjukkan bahwa auditor yang tidak dapat menjadi oreng jhujhur (orang jujur) tidak akan dapat mate ngonjhur (mati berselonjor), dalam artian auditor yang melakukan kebohongan maka jangan berharap dia akan menjadi orang yang beruntung. Auditor yang sudah berani mengesampingkan sikap integritasnya dalam proses audit maka cepat atau lambat kehancuran akan segera menimpanya.

\section{Skeptisme}


Skeptisisme profesional adalah sikap yang mencakup pikiran yang mempertanyakan dan penilaian kritis terhadap bukti audit. Skeptisisme profesional dipandang sebagai karakteristik auditor yang sangat diperlukan (Hoos et al., 2019). Auditor menggunakan pengetahuan, keterampilan, dan kemampuan yang diminta oleh profesi akuntan publik untuk melaksanakan pengumpulan dan evaluasi bukti dengan objektif, i'tikad baik dan integritas (Duska et al., 2011, p. 132), sehingga sangat tidak dibenarkan apabila auditor memberikan opini tanpa pertimbangan yang matang dari berbagai aspek.

Saloka Madura menyatakan bahwa manis jhe' dhuli kalodhu' pae' jhe' dhuli paloa yang artinya adalah manis jangan langsung ditelan pahit jangan langsung diludahkan. Saloka ini biasa disampaikan untuk menasehati orang Madura agar tidak terburu-buru menganggap baik seseorang maupun barang tanpa menelusuri dan menyelidikinya terlebih dahulu.

Perkara yang secara sepintas manis belum tentu adalah sesuatu yang bermanfaat dan tidak berbahaya, begitu juga perkara yang sepintas terasa pahit belum tentu adalah sesuatu yang berbahaya. Perkara manis namun adalah racun tentu akan berbahaya jika ditelan, begitu juga perkara pahit namun adalah jamu tradisional atau obat tentu akan bermanfaat apabila ditelan. Contoh lainnya adalah dalam menilai seseorang yang manis didepan kita belum tentu mempunyai niat baik, bahkan orang yang justru marah-marah adalah seseorang yang benar-benar peduli kepada kita. Ketika orang tua menegur keras anaknya yang malas-malasan untuk melaksanakan sholat maka sebenarnya orang tua yang demikian adalah orang tua yang memiliki kasih sayang yang sebenarnya. Teguran orang tua yang sepintas terasa pahit, sebenarnya mengandung kasih sayang yang besar. Dari contoh-contoh ini maka orang Madura tidak boleh mengambil keputusan atau memutuskan sesuatu tanpa berpikir dan mempertimbangkannya secara matang.

Dari saloka Madura ini maka auditor dapat mengambil pelajaran untuk menanamkan sikap skeptisme dalam dirinya ketika melakukan audit, sehingga auditor akan menelusuri transaksi-transaksi yang ada pada bukti-bukti audit dengan teliti dan seksama sebelum memutuskan bahwa transaksi tersebut adalah benar.

Untuk mencapai kompetensi yang memadai sebagai dasar sikap skeptisme yang harus diterapkan auditor dalam melaksanakan tugasnya maka auditor harus memiliki pendidikan dan pengalaman. Auditor tentu harus memiliki pengetahuan tentang akuntansi dan audit. Selain itu, auditor harus mampu mengetahui kapasitas kompetensi yang mereka miliki dan tidak memaksakan terhadap sesuatu yang bukan pada kemampuannya, sehingga auditor dalam kondisi tertentu harus meminta bantuan dari tenaga ahli lain dalam melaksanakan audit. Ketika auditor mengaudit perusahaan pembuat kapal, maka auditor harus meminta tenaga penilai 
untuk menilai proyek pembuatan kapal yang masih setengah jalan pada akhir periode akuntansi.

Hal ini menunjukkan bagaimana kompetensi dari auditor sangat penting, seperti Hadist Nabi SAW tentang pentingnya ilmu sebagi berikut.

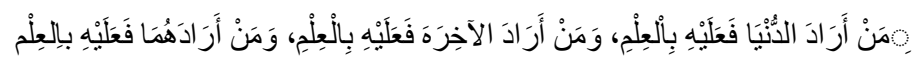

"Barangsiapa yang menginginkan dunia, maka harus dengan ilmu. Barang siapa yang menginginkan akhirat, maka harus dengan ilmu. Barang siapa yang menginginkan keduanya, maka harus dengan ilmu."

Beburughen becce' yang disampaikan melalui saloka Madura dan Hadist Nabi SAW menunjukkan bahwa skeptisme dari auditor yang berlandaskan pada kompetensi yang memadai merupakan sesuatu yang sangat penting. Terlebih tugas dan tanggunga jawab auditor kepada publik, profesi, dan Allah harus benarbenar dilaksanakan dengan sebaik-baiknya dengan prosedur-prosedur yang benar dan telah ditetapkan, sehingga kompetensi dan skepeisme dari auditor harus benar-benar diterapkan demi tercapainya fungsi dan tanggung jawab auditor yang sebenarnya.

\section{Kesimpulan}

Setiap etnis dan budaya memiliki keunikan dan mengandung etika baik bagi masyarakat. Berbagai nasehat dan petuah dari orang tua, guru, maupun pimpinan suku dapat disampaikan dengan cara-cara unik seperti melalui pribahasa khas budaya itu sendiri.

Madura menyampaikan setiap nasehat baik atau beburughen becce' dalam bentuk saloka Madura. Saloka Madura memberikan nasehat-nasehat agar supaya masyarakat selalu berperilaku baik dan menjadi bermanfaat untuk sesama. Adanya nilai-nilai luhur yang terkandung dari saloka Madura sangat cocok untuk menjadi patokan dalam menjalani hidup yang lebih baik dan bermakna, serta berguna bagi sesama karena hadist Nabi SAW menyatakan bahwa "Paling baiknya manusia adalah yang bermanfaat bagi manusia lainnya".

Kayanya nilai etika dalam nasehat baik dari saloka Madura dapat dijadikan sebuah patokan oleh auditor untuk selalu mawas diri dalam melaksanakan pekerjaan audit agar keberadaan auditor dapat bermanfaat bagi sesama, sebagaimana setiap prinsip yang harus dijaga oleh auditor telah diwanti-wanti dalam saloka Madura.

Independensi harus tertanam kuat dalam sanubari auditor layaknya pakoh ngenneng ka kaju (paku tertancap pada kayu) dan bertanggung jawab sesuai dengan tugas dan fungsinya seperti wajengan saloka Madura lakona lakone kennengnganna kennengnge (pekerjakannya kerjakan tempatnya tempati). Tanggung jawab auditor tercermin dalam pemberian opini yang tepat dimana 
opini yang tepat hanya akan diperoleh dengan prinsip skeptisme untuk mempertanyakan dan menelusuri kebenaran dari laporan keuangan layaknya nasehat dalam saloka Madura manis jhe' dhuli kalodhu' pae' jhe' dhuli paloa (manis jangan langsung ditelan pahit jangan langsung diludahkan). Selain itu, kewenangan auditor dalam memutuskan opini harus objektif dan tidak sewenangwenang layaknya nasehat mon kerras paakerres (jika kerras harus berkeris), serta menjunjung tingigi integritas layaknya nasehat oréng jhujhur maté ngonjhur (orang jujur mati berselonjor).

\section{Daftar Pustaka}

Afifah, U., Sari, R. N., Anugerah, R., \& Sanusi, Z. M. (2015). The Effect of Role Conflict, Self-efficacy, Professional Ethical Sensitivity on Auditor Performance with Emotional Quotient as Moderating Variable. Procedia Economics and Finance, 31, 206-212.

Apriliani, M., \& Abdullah, M. W. (2018). Falsafah Kesenian Tanjidor pada Pelaksanaan Corporate Social Responsibility Jurnal Akuntansi Multiparadigma, 9(2), 377-393.

Ashadi, M. M., \& Al-Farouk, G. (1992). Kosa Kata Basa Madura. Surabaya: Sarana Ilmu.

Azis, N. A., Mangoting, Y., \& Lutfillah, N. Q. (2015). Memaknai Independensi Auditor dengan Keindahan Nilai-Nilai Kearifan Lokal Siri’Na Pacce. Jurnal Akuntansi Multiparadigma, 6(1), 145-156.

Bastari, \& Fiandarti, Y. I. (2009). Kosa Kata Bahasa Madura Lengkap. Surabaya: Karya Simpati Mandiri.

Budisusetyo, S., \& Subroto, B. (2012). 'Teposliro'and'Semuci'Among Public Accountants: Do We Know, and Do We Care? Jurnal Akuntansi Multiparadigma, 3(2), 208-216.

Chiang, C. (2016). Conceptualising the linkage between professional scepticism and auditor independence. Pacific Accounting Review, 28(2), 180-200.

Dean, G., Clarke, F., \& Wolnizer, P. (2002). Auditor independence reformsrecycled ideas. Abacus, 38(2).

Djasuli, M. (2017). Etika Bisnis dan Profesi; Relevansinya Terhadap Nilai Etika Kearifan Lokal Madura sebagai Landasan Hidup Masyarakat Madura. Pamator Journal, 10(1), 1-10.

Duska, R., Duska, B. S., \& Ragatz, J. A. (2011). Accounting Ethics Second Edition. UK: Wiley-blackwell.

Efferin, S. (2015). Akuntansi, Spiritualitas, dan Kearifan Lokal: Beberapa Agenda Penelitian Kritis. Jurnal Akuntansi Multiparadigma, 6(3), 466-480.

Fitria, Y., \& Syakura, M. A. (2017). Tabir Akuntabilitas "Keroan” pada Akuntan. Jurnal Akuntansi Multiparadigma, 8(1), 90-106. 
Hoos, F., Pruijssers, J. L., \& Lander, M. W. (2019). Who's watching? Accountability in different audit regimes and the effects on auditors' professional skepticism. Journal of Business Ethics, 156(2), 563-575.

Irmawan, Y., Hudaib, M., \& Haniffa, R. (2013). Exploring the perceptions of auditor independence in Indonesia. Journal of Islamic Accounting and Business Research, 4(2), 173-202.

Jelinek, K. (2018). Will and Caroline: Accounting, professional integrity and lobbying. Journal of Accounting Education, 43, 76-88.

Johnstone, K. M., Warfield, T. D., \& Sutton, M. H. (2001). Antecedents and consequences of independence risk: Framework for analysis. Accounting Horizons, 15(1), 1-18.

Lutfillah, N. Q., Mangoting, Y., Edie Wijaya, R., \& Djuharni, D. (2016). Konstruksi Tanggung Jawab Auditor dalam Perspektif Memayu Hayuning Bawana. Jurnal Akuntansi Multiparadigma, 7(1), 36-50.

Masoud, N. (2017). An empirical study of audit expectation-performance gap: The case of Libya. Research in International Business and Finance, 41, 115 .

Misnadin, M. (2012). Nilai-Nilai Luhur Budaya Dalam Pepatah-Pepatah Madura. ATAVISME, 15(1), 75-84.

Moleong, L. J. (2005). Metodeologi Penelitian Kualitatif. Bandung: PT Remaja Rosdakarya.

Nugraha, A. P. (2017). Makna Peribahasa Madura dan Stereotip Kekerasan Pada Etnis Madura (Tinjauan Stilistika). LiNGUA, 12(2), 90-98.

Pertiwi, I. D. A. E., \& Ludigdo, U. (2013). Implementasi Corporate Social Responsibility Berlandaskan Budaya Tri Hita Karana. Jurnal Akuntansi Multiparadigma, 4(3), 430-455.

Pflugrath, G., Martinov-Bennie, N., \& Chen, L. (2007). The impact of codes of ethics and experience on auditor judgments. Managerial Auditing Journal, 22(6), 566-589.

Purnamawati, I. G. A. (2018). Dimensi Akuntabilitas Dan Pengungkapan Pada Tradisi Nampah Batu Jurnal Akuntansi Multiparadigma, 9(2), 312-330.

Zahmatkesh, S., \& Rezazadeh, J. (2017). The effect of auditor features on audit quality. Tékhne, 15(2), 79-87. 